Running Head: Can the flipped model improve performance?

\title{
Title
}

\section{Can the flipped classroom model improve students' academic performance and training satisfaction in Higher Education instructional media design courses?}

\begin{abstract}
While "flipping” a classroom has gained attention in K-12 and Secondary school programs, there has been relatively no explicit focus on its effectiveness as a teaching method for instructional media design courses in Higher Education. The purpose of this quasi-experimental study was to determine the effectiveness of the flipped classroom approach to teaching instructional media design subjects by comparing students’ academic performance and training satisfaction in traditional lecture-based instruction with those in a flipped classroom. A total of 128 undergraduate students participated voluntarily and were divided into a control $(n=62)$ and an experimental ( $n=66)$ group, respectively. The study findings indicated substantial differences in both academic performance and training satisfaction between the two groups, with the students in the experimental group performing significantly better. Specifically, the results showed some determining factors associated with training satisfaction that explain why students in flipped classes achieved notably higher mastery in the learning objectives than their control group peers. This study adds to the literature by providing evidence on how a flipped classroom can potentially benefit students’ academic performance, leading to higher training satisfaction and deeper disciplinary understanding in instructional media design courses. Keywords: instructional media design, flipped classroom, academic performance, training satisfaction
\end{abstract}


Running Head: Can the flipped model improve performance?

\section{Introduction}

Instructional design courses generally focus on creating an instructional environment, choosing effective training techniques, and selecting appropriate learning materials that can help learners to accomplish certain tasks that they were previously unable to do (Reigeluth, 2013). Due to the surge of innovation in the field of Information and Communication Technologies (ICT) as well as the emergence of online learning websites and Massive Open Online Courses (MOOCs), the domain of instructional media design has recently gained further attention. This involves discovering learning objectives and requirements for a specific educational course by designing, developing, and implementing content to meet these objectives. A combination of learning material such as slide presentations, video, podcasts, text or web pages can be used to transform information into a clear and meaningful content, thus affecting the students' levels of satisfaction and their performance (Costley \& Lange, 2016).

The use of learning technologies, however, is not always sufficient enough to satisfy students' expectations or to create a classroom environment which can increase their academic performance. Institutional constraints on time and support due to the scarcity of infrastructure, limited resources, and lack of experience or professional development opportunities for faculty to gain the technical skills and confidence needed to effectively implement active learning strategies are grave barriers in using ICT tools to their full capacity (Caswell et al., 2008). Furthermore, the delivery method for instructional design courses is still mainly focused on traditional face-to-face and relatively long lectures that passively transfer foundational knowledge to students, with little integration of practice-based, technology-focused tasks for teaching and learning (Guo et al., 2014). 
Running Head: Can the flipped model improve performance?

Nevertheless, exposing students to content materials in long lectures is considered ineffective for conceptualising and understanding the notions being taught (Lee \& Tsai, 2011).

A growing number of studies have documented significant findings in the use of a flipped classroom (FC) in different learning subjects. There is common agreement that a FC as a pedagogical strategy is likely to foster student-centred, active learning by giving students more time to work together and focus on tasks that cognitively demand and require higher-order knowledge and cognitive thinking skills (McLaughlin et al., 2014; Long et al., 2016). Despite a substantial body of research that has presented the educational potential of a FC in various Higher Education (HE) subjects, such as information systems (Davies et al., 2013), teaching and learning theories (Luo et al., 2018), or applied English for vocational education (Chuang et al., 2018), the domain of instructional media design courses has not yet been explicitly researched. There have been several small-sample studies, but most of them only address the educational value of the flipped instructional model (DeLozier \& Rhodes, 2016). Although many researchers have examined specific activities and practices frequently utilised in the FC (Chuang et al., 2018; Luo et al., 2018; Thai et al., 2017), little attention has been given to how student academic performance and training satisfaction can be influenced by a FC approach.

This quasi-experimental study aims to address the aforementioned issues by comparing instructional media design activities implemented in a traditional lecture-based class to a FC with pre-delivered learning content. In the traditional setting, instructors delivered in-class lectures to introduce new content, while in the FC they used educational technologies (e.g., online videos, lecture webcasts, text readings, and online collaborative discussions) to deliver content outside of the classroom, which students studied at their own pace before attending their class. Therefore, this study contributes to the literature by providing an in-depth description of the instructional 
Running Head: Can the flipped model improve performance?

settings in which a FC appeared to benefit students’ academic performance in instructional media design courses and resulted in greater training satisfaction compared to traditional lecturebased instruction.

\section{Literature review}

Instructors face major challenges on how to assist students in their continuous efforts for improvement and how to enhance their instructional practices. With the aim of engaging and motivate students from different socio-cognitive backgrounds, learning technologists and educators investigate the benefits of using alternative strategies and teaching methods, which include "flipping” or "inverting” a classroom as an alternative option to conventional teaching (DeLozier \& Rhodes, 2016; O’Flaherty \& Phillips, 2015). A FC is a blended learning pedagogical model that uses technology to allow for content coverage to take place outside of the classroom, with scaffolding activities to bring practice with concepts into the classroom, thereby involving students in active learning (Strayer, 2012). Particularly, in a FC students can choose the location where they receive content/instruction online and also control the pace at which they move through the online elements. The implementation of a FC involves a "fixed-schedule" instruction where students alternate between classroom-based, face-to-face, teacher-guided active learning exercises and the remote-location online delivery and instruction of the content for the given subject after class (Strayer, 2012). Students watch educational videos (webcasts) at home and do their coursework during class hours with the assistance of their peers and under the supervision of their instructor(s). This approach can assist students to participate in meaningful, instructor-guided, problem-solving learning activities and general discussions, with participants remarking that the most positive aspects were engagement and efficient use of face-to-face class time (Kostaris et al., 2017). In previous literature reviews that compared traditional and flipped 
Running Head: Can the flipped model improve performance?

classrooms (DeLozier \& Rhodes, 2016; O’Flaherty \& Phillips, 2015), students who attended the latter were reported to have (a) greater learning gains; (b) higher degrees of learning achievement, autonomy, and motivation; (c) improvements on self-efficacy and outcomes; and (d) better strategies for planning and using one's study time. Therefore, a FC can have a positive impact on students' learning gain and outcomes compared to other forms of delivery (Davies et al., 2013).

Nevertheless, research findings about the impact of FC on student learning outcomes remain mixed. For instance, several studies (Blair et al., 2016; Davies et al., 2013) have noticed no significant or only a slight difference on students' academic performance between the flipped and traditional instructional models, while in other cases FC was found to produce better results (cf. Guy \& Marquis, 2016; Long et al., 2016; Luo et al., 2018). Additionally, many faculty members are still hesitant or reluctant to adopt FC, since there are numerous factors that can make switching from a traditional to a FC setting a frustrating process (DeLozier \& Rhodes, 2016; Luo et al., 2018; O’Flaherty \& Phillips, 2015). These include, but are not limited to: (a) lack of student motivation, (b) students' resistance to classroom approaches that require their active participation in each class period and in their own time, (c) limited computer literacy, (d) increased workload for instructors in finding, selecting, and designing learning materials, (e) limited contact time, and (f) campus cultures that do not value or reward teaching innovation.

To summarise, the literature demonstrates that there has been a recent increase of research rigour and variety in measures of effectiveness in studies on the use of FC in education. Although most of these studies demonstrated learner preference for FCs, positive attitudes alone may not be sufficiently compelling evidence for educators to convert to a FC approach (Chen et al., 2017). Due to lack of conclusive findings, more solid evidence on the effect of FC on 
Running Head: Can the flipped model improve performance?

academic performance and student satisfaction is warranted (Chuang et al., 2018; Luo et al., 2018; O’Flaherty \& Phillips, 2015). This study aspires to assess whether a FC can impact learning effectiveness for instructional media design courses - thus leading to better academic performance and training satisfaction - by comparing a flipped and a traditional class. The consideration for this study was inspired by two previous literature reviews (DeLozier \& Rhodes, 2017; O’Flaherty \& Phillips, 2015) that presented direct evidence on how student academic performance and training satisfaction could be positively affected by a FC approach when compared to a traditional (lecture-based) teaching. The addressed research questions (RQ) are the following:

$R Q 1$. Is there any significant difference in academic performance between students who participated in a FC and their peers who received traditional instruction?

RQ2. Is there any significant difference in training satisfaction among students who participated in a FC and their peers who received traditional instruction?

\section{Research design}

\section{Methodology}

The present study used a non-equivalent control group design with pretest and posttest measures, as this is considered "one of the most commonly used quasi-experimental designs in educational research” (p. 283, Cohen et al., 2007). It is represented as follows:

$\begin{array}{lllll}\text { Experimental Group (EG): } & N R & O_{1} & X & O_{2} \\ \text { Control Group (CG): } & N R & O_{1} & O_{2}\end{array}$

In this design $N R$ represents non-randomisation, $O_{1}$ represents the pretest (i.e., questionnaires or tests that participants are required to complete prior to the implementation of a treatment), $X$ represents the implemented treatment (i.e., the FC teaching), and $\mathrm{O}_{2}$ represents 
Running Head: Can the flipped model improve performance?

posttests (Cohen et al., 2007). Although only the experimental group underwent the treatment process, both groups (experimental and control) completed a pre- and posttest. Even though comparison groups should be similar in as many characteristics as possible, the assignment of participants in the two groups was deliberately non-randomised. This was done in a way to avoid possible bias in the study results (Shadish et al., 2002). The authors wanted the experimental group to contain experienced web users so as to minimise the novelty effect and to ensure that students would be able to use the web sources efficiently.

Regarding construct validity, the suggestions stated in the study by Kostaris et al. (2017) were followed. Both content and construct validity were ensured at every stage of the process by the practitioner and external reviewers who were experts in the field of Computer Science and educational technologies. The latter supervised the experiment and provided critical feedback, firstly on interpreting the data collected by the practitioner (e.g., survey data), and secondly on eliciting insights from data analysis for answering the research questions. The experiment was conducted in Greek.

\section{Participants}

All participants were undergraduate students who were enrolled in the third-year module "Instructional design and learning theories in Informatics" at the Computer and Informatics Engineering Department of the Eastern Macedonia and Thrace Institute of Technology. A total of 128 students (101 males and 27 females) aged between 19-23 years $(M=20.5, S D=3.4)$ participated voluntarily in this study. Despite the significantly fewer female participants the sample was regarded as acceptable, since this gender ratio is typical in Greek ICT-focused undergraduate courses and a balanced sample would have been either too small or unattainable. The control group (CG) comprised 62 participants (males, $n=48$, females, $n=14$ ) and the 
Running Head: Can the flipped model improve performance?

experimental group (EG) consisted of 66 participants (males, $n=53$, females, $n=13$ ) who were taught using lecture-based instruction and flipped instruction, respectively. There was no loss of participants in either group throughout the study, so there was no attrition which could have threatened the internal validity of the research.

\section{Instruments}

\section{Pre- and posttest on students' academic performance}

To measure student academic performance before and after the educational intervention, a questionnaire, consisting of 12 multiple choice and 4 open-ended questions, was used to assess students on the course objectives. The content of the pre- and posttest was the same, but the test items were reordered to avoid the same set response effect. The value of Cronbach's $a$ of pre-and posttests for the CG was 0.75 and 0.77 respectively, while for the EG it was 0.71 and 0.73 . In all cases, Cronbach’s alpha (a) value implied high reliability in internal consistency.

\section{Training satisfaction}

To assess the training satisfaction, the study used Tello et al.’s (2006) questionnaire, which contained 12 items on a 5-point Likert scale separated into three components: (a) objectives and content; (b) method and training context; and (c) usefulness and overall rating. The internal consistency coefficient (Cronbach's $\alpha$ ) for the post questionnaire was 0.91 for the CG and 0.96 for the EG.

\section{Procedure}

The study was conducted over a 12-week period, with 2 hours of lectures and 4 hours of lab-based workshops per week. An instructor gave lectures on contemporary learning theories and models, including, among others, Behaviourism, Constructionism, and (social-) 
Running Head: Can the flipped model improve performance?

Constructivism. A second instructor ran practical workshops designed to help students apply in practice the concepts learnt in class by creating educational content using specific ICT tools.

To attain knowledge through authentic learning experiences, students were put into the real-life situation of producing content for an existing textbook. Specifically, participants were assessed on 4 practical assignments which included the production of educational content in the Informatics textbook used in Greek secondary schools. The participants of each group (CG and EG) were divided into 5-member assignment groups. Each assignment group was given learning units from the Informatics textbook, for which they had to produce supplemental learning material and publish it in a blog along with the learning objectives, abstract, and main concept of each learning unit. Students had also two weeks following their final presentation to improve their work based on the formative feedback they had received from their peers and instructor during and after the completion of each assignment. Additionally, they were required to produce a report on the learning theories they had applied to their projects.

The main issue the instructors had to solve was logistical: "How can a single person manage such a large number of students with only 4 hours of workshops per week?" The answer was to divide the participants into 4 sub-groups of about 30 students each. Specifically, CG was split into CG1 and CG2, while EG was divided into EG1 and EG2, and a 2-hour workshop run for each group fortnightly. An alternative solution of delivering weekly 1-hour workshops was rejected because it was not possible to reach the learning objectives for each session in such a limited amount of time. The first workshop was an introduction to the module, while the last was used for students to present their work. In every other session, a different part of the course curriculum was covered and a new project was assigned to the participants. 
Running Head: Can the flipped model improve performance?

Since this study had a non-randomised sample, there were key concerns about methods of conscious control of implicit attitudes between male and female participants. Despite the genderimbalanced sample, this study complied with the internal rule of the institutional operation that required a ratio of 1 female to 5 males for all research projects (20\%). In addition, to avoid having groups containing only students with either low or high marks, which could potentially limit the diversity of the participants’ opinions, the instructors ensured heterogeneity by including in each group participants who scored across all ranges in the pretest.

Both the CG and the EG shared the same lecture on learning theories every week. However, different delivery methods were used for the lab-based workshops, which were delivered to each group every other week (e.g., week 1, 3, 5... for CG1 and CG2, and week 2, 4, 6... for EG1 and EG2). A detailed description of both in-class and out-of-class workshop activities used for both groups is presented below.

Both CG1 and CG2 followed a traditional classroom approach where the first 90 of the 120 minutes in-class session were devoted to lecture and discussion, with the instructor demonstrating various authoring/production tools and introducing techniques for developing educational material. The participants could then ask questions, while the remaining time was spent on problem-solving and development of media assets. At the end of every session, participants were assigned a project to apply and present their gained knowledge. This project included producing an educational blog, educational videos, presentations, and an educational interactive comic. They then had 14 days until the next workshop to submit their work. During that time, they could communicate and receive feedback from their peers and/or their instructor via Moodle forums, emails, or Skype. 
Running Head: Can the flipped model improve performance?

Direct instruction (i.e., the explicit scripted presentation or delivery of information or a task) was removed from class time for EG1 and EG2. Both groups followed a FC approach instead, which consisted of computer-assisted out-of-class personal instruction and interactive inclass group learning activities. A week ahead of every workshop, the instructor prepared and uploaded learning material (e.g., lecture webcasts, guided readings of textbooks and research papers, presentations, and notes). Students could then study the material at their own pace according to their knowledge levels; they were able to selectively "watch" the lectures, but also replay key and difficult content as often as they wished. By choosing freely the most suitable method to acquire knowledge and by repeating their exposure to the learning resources, students strengthened and deepened their understanding of the material. Students were asked to prepare in advance by watching short-length videos - up to 6-minute-long, since learners reportedly lose their engagement with longer videos (Guo et al., 2014) - and studying the accompanying reading material before going to class. They could also communicate with their peers and their instructor via an online forum in order to address any questions that may have arisen.

This preparation enabled the instructors to make the workshop more interactive and less lecture-heavy. Instead of spending 90 minutes lecturing as with CG1 and CG2, this time was more effectively used by presenting key points and the application of concepts in-depth, while also answering student questions, and providing students with opportunities to apply the taught content through hands-on, active learning exercises. During the remaining in-class time participants were engaged in problem-solving activities that enriched their understanding of the prescribed educational material (e.g., participating in group discussions about the presented case studies and problems, presenting student-created content, etc.). This allowed for active and constructivist learning. At the end of every workshop, EG1 and EG2 students were assigned the 
Running Head: Can the flipped model improve performance?

same project as that given to CG1 and CG2. Likewise, they had 14 days to submit their coursework and prepare for the next class. During that time, they could contact their peers and instructor via the aforementioned communication channels.

\section{Experimental setup}

The experiment was conducted as follows (Figure 1): In the first week, all participants completed a demographic questionnaire followed by a pretest to determine their prior domain knowledge. This pretest included a set of 6 open-ended questions relevant to the conceptual domain knowledge of instructional design (e.g., the implementation of instructional models such as Behaviourism and Constructionism with ICT, the use of digital storytelling in education including interactive comics and graphic novels, best practices to build presentations, practical questions on blogging, the development of educational videos, etc.). A marking scheme rubric was used by the instructors to assess the students' understanding of learning theories and their applications, ranging from 5 (adequate answer) to 0 points (incorrect/no answer). The perfect score for both the pre- and posttest was 30. Students were then divided into sub-groups of the CG (i.e., CG1, CG2) and the EG (i.e., EG1, EG2) according to their demographics and pretest scores, which ensured that all participants' characteristics (i.e., age, gender, familiarity with ICT) were balanced equally among each group. 
Running Head: Can the flipped model improve performance?

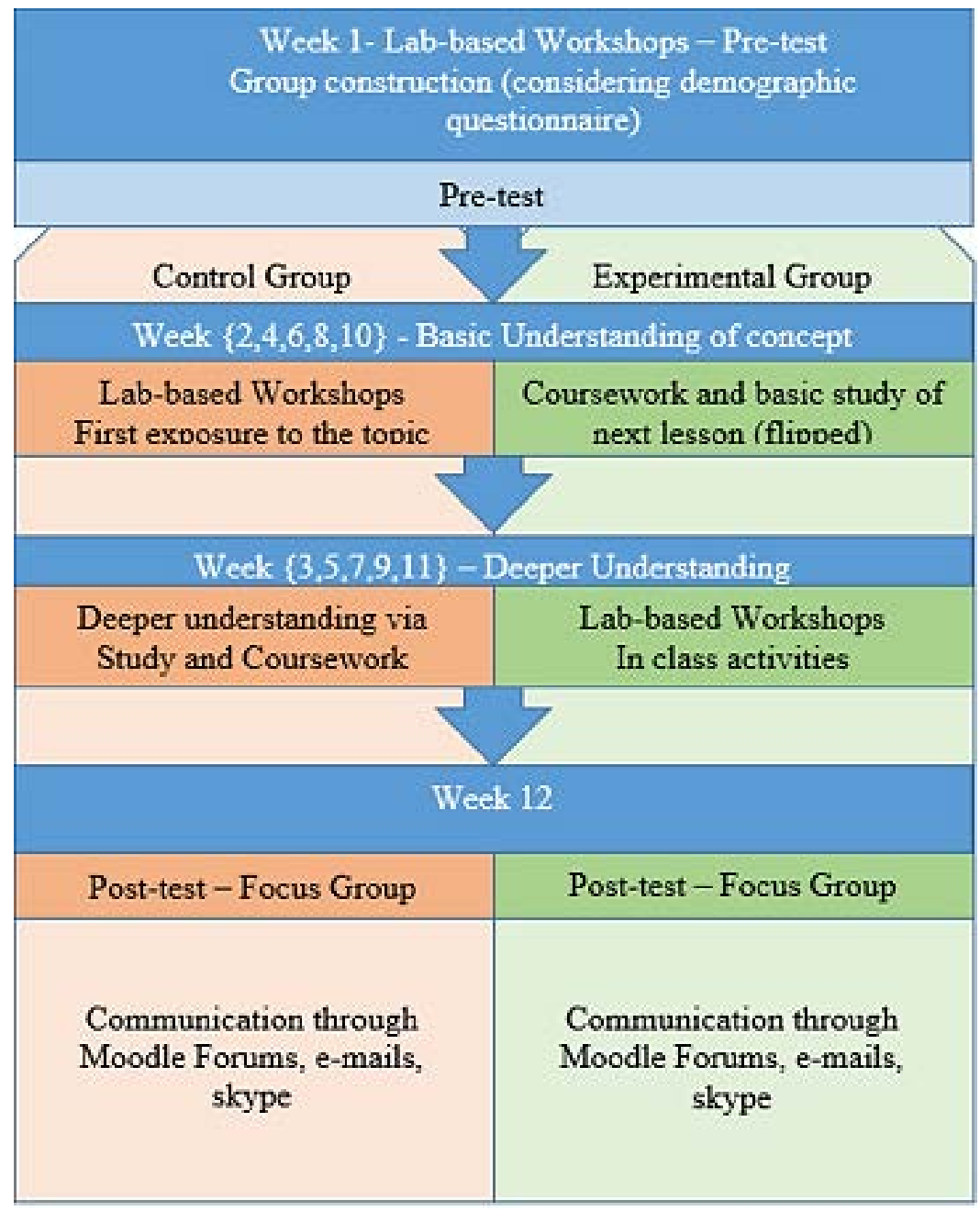

Figure 1: Study design

The treatment began in the second week. The timetable for each group included a 2-hour lecture every week and a 2-hour workshop every other week. All students shared the same module aims, learning outcomes, and coursework, with the CG being taught through a lecturebased instruction and the EG following the previously described flipped instruction. Students who required remedial assistance received one-to-one support from their instructor.

At the end of the experiment (Week 12), all participants undertook a posttest that measured their academic achievements. In order to gather data on the social validity of the study (i.e., to validate the social significance of the treatment goals and the social appropriateness of the intervention strategies used), as well as to assess whether the outcomes achieved were 
Running Head: Can the flipped model improve performance?

acceptable, relevant, and useful to students (Cruz-Jesus et al., 2016), all participants also completed online the following: i) a posttest questionnaire on academic performance and outcomes, ii) a questionnaire on training satisfaction, and iii) a demographic survey.

\section{Data analysis}

All analyses were conducted using the Statistical Package for the Social Sciences (SPSS) to ensure the reliability of the descriptive results. Descriptive statistics were applied using frequency and percentages, while similarities and differences in the results were presented on plot diagrams. An independent sample t-test was also conducted to determine the effects of the FC in regard to student academic performance.

For course training satisfaction, one-way multivariate analysis of variance (MANOVA) was conducted between the CG and the EG in terms of "Objectives and content”, "Method and training context”, and “Usefulness and overall rating” which were regarded as dependent variables. The statistical significance level was set at $\mathrm{p}<.05$ as an acceptable value for reliability, reflecting on reasonable internal consistency and usability of the variables to describe students’ expectations (Tavakol \& Dennick, 2011).

\section{Results}

\section{Demographics}

To ensure the experimental validity, it was crucial that there was no 'digital inequality' between participants, i.e., there were no digital inequalities regarding their opportunities to access ICT and use the Internet for a wide variety of activities (Cruz-Jesus et al., 2016). It was imperative that EG participants, who were required to use online courseware such as presentations, video tutorials, and readings prior to class, had sufficient technical skills to fulfill these tasks. The main aim was to analyse the selected demographic characteristics of participants 
Running Head: Can the flipped model improve performance?

in order to determine if they had the ability to access and use the provided online educational material (Table 1).

There was a similar proportion in the gender balance for both CG and EG. Participants were predominantly male, as is the norm for this module. Most participants in both groups used Social Network Services (SNS) daily (85.5\% of CG and $86.4 \%$ of EG) and visited the institutional Learning Management System (LMS) a few times per week or more (77.4\% of CG and $72.7 \%$ of EG). Finally, almost all participants (96.8\% of CG and $97 \%$ of EG) owned a smartphone with Internet access and video playback capabilities and were capable of using new educational technologies on it (e.g., LMS and SNS). Therefore, the course material was easily accessible to almost all enrolled participants.

Table 1. Frequency and percentage of the demographic characteristics

\begin{tabular}{|c|c|c|c|c|c|c|c|}
\hline & & \multicolumn{2}{|c|}{ Control Group (CG) } & \multicolumn{2}{|c|}{ Experimental Group (EG) } & \multicolumn{2}{|c|}{ Total } \\
\hline & & $\mathbf{n}$ & $\%$ & n & $\%$ & n & $\%$ \\
\hline \multirow[t]{2}{*}{ Gender } & Male & 48 & $77.4 \%$ & 53 & $80.3 \%$ & 101 & $78.9 \%$ \\
\hline & Fernale & 14 & $22.6 \%$ & 13 & $19.7 \%$ & 27 & $21.1 \%$ \\
\hline Total & & 62 & $100.0 \%$ & 66 & $100.0 \%$ & 128 & $100.0 \%$ \\
\hline \multirow[t]{5}{*}{ SNS Usage } & Nexer & 1 & $1.6 \%$ & $\mathbf{1}$ & $1.5 \%$ & 2 & $1.6 \%$ \\
\hline & Rarely & 2 & $3.2 \%$ & 3 & $4.5 \%$ & 5 & $3.9 \%$ \\
\hline & Fex times per month & 2 & $3.2 \%$ & 1 & $1.5 \%$ & 3 & $2.3 \%$ \\
\hline & Few times per week & 4 & $6.5 \%$ & 4 & $6.1 \%$ & 8 & $6.3 \%$ \\
\hline & Daily & 53 & $85.5 \%$ & 57 & $86.4 \%$ & 110 & $85.9 \%$ \\
\hline Total & & 62 & $100.0 \%$ & 66 & $100.0 \%$ & 128 & $100.0 \%$ \\
\hline \multirow[t]{5}{*}{ LMS wage } & Nexer & 1 & $1.6 \%$ & 3 & $4.5 \%$ & 4 & $3.1 \%$ \\
\hline & Rarely & 4 & $6.5 \%$ & 2 & $3.0 \%$ & 6 & $4.7 \%$ \\
\hline & Fex times per month & 9 & $14.5 \%$ & 13 & $19.7 \%$ & 22 & $17.2 \%$ \\
\hline & Fex timex per week & 36 & $58.1 \%$ & 35 & $53.0 \%$ & $\tau 1$ & $55.5 \%$ \\
\hline & Daily & 12 & $19.3 \%$ & 13 & $19.7 \%$ & 25 & $19.5 \%$ \\
\hline Total & & 62 & $100.0 \%$ & 66 & $100.0 \%$ & 128 & $100.0 \%$ \\
\hline \multirow{3}{*}{$\begin{array}{l}\text { Smartphone } \\
\text { with Internet } \\
\text { access } \\
\text { Total }\end{array}$} & No & 2 & $3.2 \%$ & 2 & $3.0 \%$ & 4 & $3.1 \%$ \\
\hline & Yex & 60 & $96.8 \%$ & 64 & $97.0 \%$ & 124 & $96.9 \%$ \\
\hline & & 62 & $100.0 \%$ & 66 & $100.0 \%$ & 128 & $100.0 \%$ \\
\hline
\end{tabular}

\section{Students’ academic performance}

In order to answer if there was any significant difference in performance between students who participated in the FC and their peers who participated in a traditional class setting 
Running Head: Can the flipped model improve performance?

(RQ1), pre- and posttest scores were statistically analysed. The Levene's test for homogeneity of variance was conducted on the pretest scores. The results showed that the homogeneity test had not achieved statistical significance; therefore, a t-test could be applied. An independent sample $t$-test was conducted on pretest scores collected from both groups. Results indicated that there was no significant difference between the two groups ( $t$-value $=-.69, p=.945)$, which showed that they were similar in abilities before this experiment was conducted.

The posttest examined student academic performance. Initially, a boxplot was created to demonstrate potential differences between student groups on the pre- and posttest scores (Figure 2). It can easily be observed from the boxplot diagram that despite the similar pretest scores of the two groups, EG students had higher scores in the posttest.

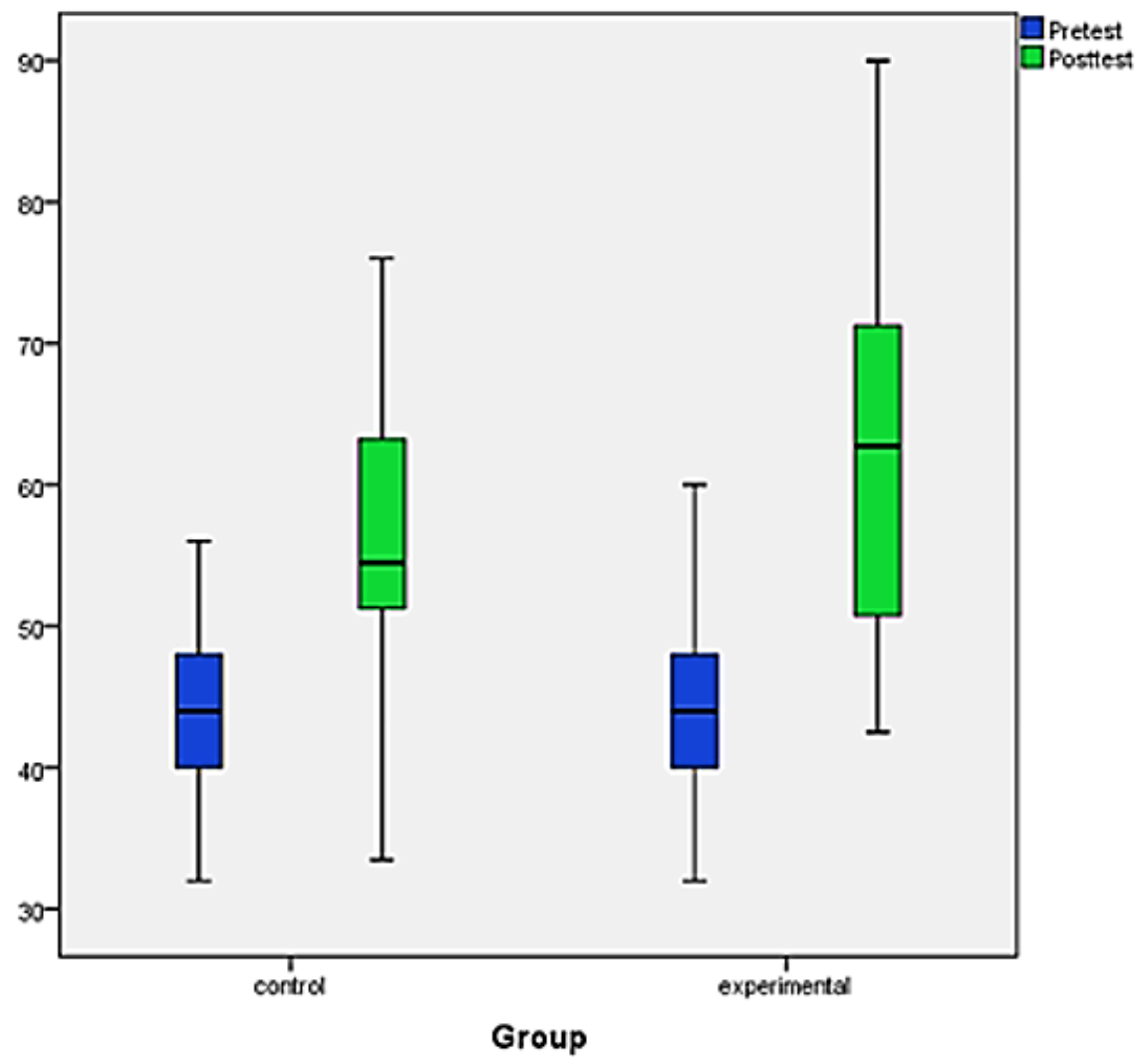

Figure 2: A boxplot diagram for pre- and posttest scores for each group 
Running Head: Can the flipped model improve performance?

To find out whether this difference was statistically significant, a t-test on the posttest scores was conducted. Table 2 contains the pre- and posttest results for student academic performance.

Table 2. Independent sample $t$-test for pretest and posttest between the groups based on their academic performance

\begin{tabular}{lllllll}
\hline $\begin{array}{l}\text { Academic } \\
\text { performance }\end{array}$ & Group & Mean & $S D$ & $M D$ & $t$-value & $p$ \\
\hline Pretest & CG & 43.129 & 5.66 & & & \\
& EG & 43.060 & 5.57 & 0.068 & 0.69 & 0.945 \\
Posttest & CG & 55.770 & 11.02 & & & \\
& EG & 61.462 & 12.33 & -5.69 & -2.746 & 0.007 \\
\hline Note. ${ }^{*} p<.05 . E G$ & Experimental group, $C G=$ Control group, $S D=$ Standard deviation, $M D=$ mean difference
\end{tabular}

There was no substantial difference between academic achievement for CG and EG students in the pretest; the CG mean scores of pretest performance $(M=43.12, S D=5.66)$ were similar to those of EG $(M=43.06, S D=5.57)$. However, there was a difference in the posttest scores between the two groups, with the EG mean scores $(M=61.46, S D=12.33)$ being significantly better $(\mathrm{p}=0.007<0.05)$ than the $C G$ ones $(M=55.77, S D=11.02)$.

\section{Training satisfaction}

To answer whether there was any significant difference in training satisfaction between the students of the two groups (RQ2), a multivariate analysis of variance (MANOVA) was conducted to analyse the results. Table 3 provides descriptive statistics, which include means and the standard deviation for the dependent variables "Objectives and content”, "Method and training context”, and "Usefulness and overall rating”.

Table 3. Descriptive statistics for training satisfaction questionnaire

\begin{tabular}{lcccc}
\hline & Group & $\mathrm{n}$ & Mean & $S D$ \\
$\begin{array}{l}\text { Objectives and } \\
\text { content }\end{array}$ & CG & 62 & 3.37 & .095 \\
Method and & EG & 66 & 3.96 & .092 \\
training context & CG & 62 & 3.55 & .080 \\
Usefulness and & EG & 66 & 3.99 & .078 \\
overall rating & CG & 62 & 3.31 & .099 \\
& EG & 66 & 3.81 & .096 \\
\hline
\end{tabular}

Note. ${ }^{*} p<.05 . E G=$ Experimental group,$C G=$ Control group, $S D=$ Standard deviation 
Running Head: Can the flipped model improve performance?

The results from MANOVA revealed a significant difference in all three variables between the CG and EG (Wilk's $\Lambda=.85, F=6.88, p<.05, \eta^{2}=.143$ ). Therefore, univariate $F$ tests were conducted for these three variables, the results of which are shown in Table 4 . The latter indicated a significant difference in "Objectives and content" $\left(p<.05, \eta^{2}=.137\right)$, “Method and training context” ( $\left.p<.05, \eta^{2}=.108\right)$, and “Usefulness and overall rating” ( $p<$ $.05, \eta^{2}=.95$ ) between the two groups. Thus, student satisfaction was significantly higher in the EG than in the CG.

Table 4. Summary of one-way MANOVA results for training satisfaction questionnaire

\begin{tabular}{lccccccc}
\hline DV & GV & $S S$ & $d f$ & $M S$ & $F$ & $p$ & Partial $\eta^{2}$ \\
\hline $\begin{array}{l}\text { Objectives and } \\
\text { content }\end{array}$ & Group & 11.28 & 1 & 11.28 & $17.16^{*}$ & .000 & .137 \\
$\begin{array}{l}\text { Method and } \\
\text { training context }\end{array}$ & & 6.08 & 1 & 6.08 & $15.12^{*}$ & .000 & .108 \\
$\begin{array}{l}\text { Usefulness and } \\
\text { overall rating }\end{array}$ & & 8.03 & 1 & 8.03 & $9.20^{*}$ & .000 & .95 \\
\hline
\end{tabular}

Note. ${ }^{*} p<.05, D V=$ Dependent Variable, $G V=$ Grouping Variable, $S S=$ Sum of Squares, $M S=$ Mean Square

\section{Discussion}

The results of this study indicate that the FC intervention had a positive impact on students' academic performance in comparison to a traditional learning setting. Despite participants from both CG and EG receiving low scores in the initial pretest, EG students outperformed their CG peers as evidenced by the domain knowledge posttest results. These findings are in line with previous studies (McLaughlin et al., 2014; O’Flaherty \& Phillips, 2015; Guy \& Marquis, 2016) and suggest that a FC can offer flexibility with actual gain in performance when compared to the traditional lecture-based instruction.

The technology-enhanced FC was effective, engaging, and facilitated active learning better than the conventional instructional setting, which is consistent with previous findings (Blair et al., 2016; Chuang et al., 2018; Luo et al., 2018). Students were highly satisfied with their training and maintained a positive attitude during their training sessions (Costley \& Lange, 
Running Head: Can the flipped model improve performance?

2016; Long et al., 2016; Thai et al., 2017). A FC approach also converted the passive acceptance in traditional classroom learning into self-exploration by respecting the individual characteristics of cognitive learning. This could be a particularly valuable option for students with accessibility concerns, such as when closed captions are provided for people with hearing impairment. Furthermore, learning in a FC fostered deeper disciplinary learning, as it allowed instructional media design students to experience first-hand the importance of producing highquality instructional material. Therefore, a FC approach could be considered well-suited for instructional media design courses.

\section{Conclusion}

The purpose of this study was to compare a FC to a traditional lecture-based approach for instructional media design courses in order to assess its effect on students’ training satisfaction and academic performance. The student-centred instructional approach of a FC was successful in both content coverage and acquisition of disciplinary habits of mind. EG students spent more time on active learning in the classroom and showed significantly higher satisfaction levels in all three components of the training satisfaction questionnaire, which was reflected in their positive attitude during their training sessions. Furthermore, the study findings reinforce the notion that video lecturing can improve both students’ learning experience and satisfaction.

There are notable implications for practice and policy resulting from this study’s findings that can be used to enhance the effectiveness of a FC for instructional media design courses. Firstly, the learning content should be platform-independent and readily accessible, so that every student has the ability to prepare for a lesson. The use of ICT tools and SNS is also recommended, since students are expected to use in the classroom the same technology as they 
Running Head: Can the flipped model improve performance?

do for personal communication. Additionally, classroom contact time and traditional homework time should be reversed, so that students can acquire knowledge by doing their homework, and then practise their skills in class where the instructor can give them guided coaching. Finally, authentic learning should be provided to students (e.g., by allowing them to explore, discuss, and construct concepts and relationships in contexts that involve real-world scenarios and problemsolving strategies) as this can foster deeper disciplinary learning, increase their motivation, and improve their performance.

Based on the above, the contribution of this study is threefold. Firstly, it gives advice and suggestions to educators who want to incorporate FC into their teaching practice. Secondly, it offers researchers insight into the effectiveness of a flipped method in instructional media design courses. Thirdly, it provides evidence that well-designed activities in a FC can potentially increase students’ academic performance and satisfaction.

\section{Limitations and future work}

The data may be deemed insufficient for drawing generalisable conclusions about the flipped learning model. There are some key limitations in this study that should be considered when interpreting the current findings. There is a gender imbalance in the sample due to the fact that there is a disproportionate number of males to females in the department where this study was conducted, which limits external validity. Participants in an instructional media design course may have different characteristics and computer literacy skills from students in nontechnical courses. The consequence is that such variances can influence students' academic performance and training satisfaction. Even if a non-randomised experiment is conducted successfully, it is impossible to exclude all potential threats to internal validity, such as previous learning experience, perceptions of using media devices, and instrumentation. Although this 
Running Head: Can the flipped model improve performance?

study was able to compare students' academic performance and training satisfaction between two groups, it was not easy to identify whether the success of the EG relied explicitly upon the instructional videos, podcasts, presentations, and lecture notes. Additionally, it was not possible to track the number of times each participant accessed the course's digital resources and the amount of time s/he spent studying them.

Future works on the FC should include controlled mixed-method experiments of greater duration and sample size. The application of gamification techniques as a means to maximise enjoyment and increase student motivation should also be investigated. Finally, qualitative data including student interviews, focus groups, and in-class observations may enrich the quantitative data and need to be considered.

\section{Statements on open data, ethics, and conflict of interest}

- The data can only be accessed in an anonymous form by contacting the first author.

- The study was undertaken in line with Eastern Macedonia and Thrace Institute of Technology ethics procedures and guidelines.

- There is no conflict of interest in the study being presented here.

\section{References}

Blair, E., Maharaj, C., \& Primus, S. (2016). Performance and perception in the flipped classroom. Education \& Information Technologies, 21(6), 1465-1482.

Caswell, T., Henson, S., Jensen, M., \& Wiley, D. (2008). Open content and open educational resources: Enabling universal education. The International Review of Research in Open and Distance Learning, 9(1), 1-11.

Chen, F., Lui, A.M., \& Martinelli, S.M. (2017). A systematic review of the effectiveness of flipped classrooms in medical education. Medical Education, 51(6), 585-597. 
Running Head: Can the flipped model improve performance?

Chuang, H.-H, Weng, C.-Y., \& Chen, C.-H. (2018). Which students benefit most from a flipped classroom approach to language learning? British Journal of Educational Technology, 49(1), 56-68.

Cohen, L., Manion, L., \& Morrison, K. (2007). Research methods in education. New York: Routledge.

Costley, J. \& Lange, C. (2016). The effects of instructor control of online learning environments on satisfaction and perceived learning. Electronic Journal of e-Learning, 14(3), 169-180.

Cruz-Jesus, F., Vicente, M.R., Bacao, F., \& Oliveira, T. (2015). The education-related digital divide: An analysis for the EU-28. Computers in Human Behavior, 56(5), 72-82.

Davies, R.S., Dean, D.L., \& Ball, N. (2013). Flipping the classroom and instructional technology integration in a college-level information systems spreadsheet course. Educational Technology Research \& Development, 61(4), 563-580.

DeLozier, S. \& Rhodes, M. (2016). Flipped classrooms: A review of key ideas and recommendations for practice. Educational Psychology Review, 29(1), 141-151.

Guo, P.J., Kim, J., \& Rubin, R. (2014). How video production affects student engagement: An empirical study of MOOC videos. In Proceedings of the $1^{\text {st }}$ ACM conference on Learning (pp. 41-50). ACM: New York, NY, USA.

Guy, R. \& Marquis, G. (2016). The flipped classroom: A comparison of student performance using instructional videos and podcasts versus the lecture-based model of instruction. Issues in Informing Science and Information Technology, 13(1), 1-13.

Kostaris, C., Sergis, S., Sampson, D.G., Giannakos, M.N., \& Pelliccione, L. (2017). Investigating the potential of the flipped classroom model in K-12 ICT teaching and learning: An action research study. Educational Technology \& Society, 20(1), 261-273. 
Running Head: Can the flipped model improve performance?

Lee, S. W.-Y. \& Tsai, C.-C. (2011). Students’ perceptions of collaboration, self-regulated learning, and information seeking in the context of Internet-based learning and traditional learning. Computers in Human Behavior, 27(2), 905-914.

Long, T., Cummins, J., \& Waugh, M. (2016). Use of the flipped classroom instructional model in higher education: instructors’ perspectives. Journal of Computer in Higher Education 29(2), 179-200.

Luo, A., Yang, T., Xue, J., \& Zuo, X. (2018). Impact of student agency on learning performance and learning experience in a flipped classroom. British Journal of Educational Technology. DOI: 10.1111/bjet.12604

McLaughlin, J. E., Roth, M.T, Glatt, D.M., Gharkholonarehe, N., Davidson, C.A., Griffin, L.M., Esserman, D.D., \& Mumper, R.J. (2014). The flipped classroom: a course redesign to foster learning and engagement in a health professions school. Academic Medicine, 89(2), 236243.

O’ Flaherty, J. \& Phillips, C. (2015). The use of flipped classrooms in higher education: A scoping review. The Internet and Higher Education, 25(4), 85-95.

Reigeluth, C.M. (Ed.). (2013). Instructional design theories and models: An overview of their current status. Routledge.

Shadish, W., Cook, T., \& Campbell, D. (2002). Experimental and quasi-experimental designs for generalized causal inference. Boston: Houghton Mifflin Company.

Strayer, J.F. (2012). How learning in an inverted classroom influences cooperation, innovation and task orientation. Learning Environments Research, 15(2), 171-193.

Tavakol, M. \& Dennick, R. (2011). Making sense of Cronbach’s alpha. International Journal of Medical Education, 2(3), 53-55. 
Running Head: Can the flipped model improve performance?

Tello, F., Moscoso, C.S., Garcia, B.I., \& Chaves, S.S. (2006). Training satisfaction rating scale. European. Journal of Psychological Assessment, 22(4), 268-279.

Thai, N.T.T., De Wever, B., \& Valcke, M. (2017). The impact of flipped classroom design on learning performance in higher education: Looking for the bets "blend” of lectures and guiding questions with feedback. Computers \& Education, 107, 113-126. 